\title{
Physical activity guidelines for preschoolers: a call for research to inform public health policy
}

\begin{abstract}
Helen Skouteris
Associate Professor in Developmental Psychology

Daniela Dell'Aquila BSocSci(Psych) PostGradDip (Psych) Research Assistant

Louise A Baur BSc(Med), PhD, FRACP, Professor and Deputy Associate Dean

Genevieve M Dwyer

MAppSc(Phty),

PostgradCert (AdultEd\&Train), PhD Lecturer $^{2}$

Marita P McCabe $\mathrm{PhD}$, Alfred Deakin Professor of Psychology

Lina A Ricciardelli Associate Professor

Matthew

Fuller-Tyszkiewicz

Lecturer

1 School of Psychology, Deakin University, Melbourne, VIC

2 Discipline of Paediatrics and Child Health, University of Sydney, Sydney, NSW.

hysical activity is one of a number of factors that influence the healthy growth and development of children. ${ }^{1}$ The value of physical activity for young children is beyond doubt, and lack of adequate physical activity is viewed as a major contributing factor to overweight and obesity, which can track into adulthood and pose many other cardiovascular and health risks. ${ }^{2-5}$

Given that early childhood is a critical period for the establishment of eating and activity behaviour, ${ }^{6}$ prevention strategies to ensure that children develop healthy physical activity behaviour should start as early in life as possible. ${ }^{7}$ Children under the age of 5 years are commonly defined as infants when aged between birth and 1 year, as toddlers when aged between 1 and 3 years, and as preschoolers when aged 3 to 5 years. In this article, we focus on these age groups, as it is in these early years that behaviour is more malleable than in later childhood. We outline the global recommendations for physical activity for children, and the implications of these recommendations when we consider current data on preschooler physical activity in Australia. We also aim to clearly identify gaps in the literature around this topic and to suggest recommendations for future research and public health policy.

\section{Preschool physical activity guidelines around the world}

helens@deakin.edu.au

MJA 2012; 196: 174-176 doi: 10.5694/mjall.11015

Editorial p 152

Perspective p 165

Letter $p 171$

Research p 184, p 189

A search using search engines Google and Google Scholar was conducted in June 2011. We also conducted a multidatabase search using EBSCOhost (http://www. ebscohost.com/) to retrieve journal articles that have cited physical activity recommendations or guidelines in children aged $\leqslant 5$ years. Most guidelines/recommendations were retrieved from government or organisational websites. These are summarised in Box 1 and described in more detail online in Box 2 (http://mja.com.au/10.5694/ mja11.11015). Note that the words "recommendation" and "guideline" have been used interchangeably in reference to the appropriate dose-response of physical activity to yield health benefits in children. The original term used in its exact wording for each country or organisation is given in Box 2 online. To our knowledge, the countries listed are the only countries with national guidelines or recommendations for physical activity that include children $\leqslant 5$ years of age. In addition, our review includes
Sumnary

- There are many challenges in developing evidencebased physical activity guidelines for preschoolers that can ensure health benefits for children.

- Guidelines for the preschool years have recently been developed in several countries, but there are notable inconsistencies in the amount of physical activity regarded as sufficient for this age group.

Given the currently high prevalence of childhood obesity, there is an urgent need for evidence-based studies to inform the development of community-targeted programs to ensure healthy levels of physical activity in young children.

- Our article outlines the global recommendations for physical activity for children $\leqslant 5$ years of age. We identify gaps in the literature and suggest recommendations for future research and public health policy.

guidelines that mentioned this age group when developing guidelines for older children or that considered preschoolers in their proposals for future recommendations. We also consider guidelines or recommendations provided by the World Health Organization, ${ }^{15}$ and the Centers for Disease Control and Prevention ${ }^{19}$ and the National Association for Sport and Physical Education $(\mathrm{NASPE})^{8}$ in the United States.

The Australian guidelines ${ }^{11}$ and recently released United Kingdom guidelines ${ }^{9}$ are, to our knowledge, the only government-endorsed guidelines that have provided recommendations in age-appropriate categories. Ireland has grouped together children aged 2-18 years, recommending that children in this age range should be active at a moderate-to-vigorous level for at least 60 minutes every day. ${ }^{10}$ However, current UK-wide physical activity guidelines for children aged $\leqslant 5$ years, which model those from Australia, recommend that preschoolers be physically active every day for at least 3 hours, spread throughout the day. This activity should include both structured and unstructured free play. ${ }^{9}$ We argue that age groupings are needed because toddlers and preschoolers, school-aged children and adolescents are physiologically and developmentally different from each other. These developmental differences need to inform age-specific recommendations.

NASPE has also released specific guidelines for preschoolers, ${ }^{8}$ recommending 60 minutes of structured physical activity and up to several hours of unstructured play for this age group. These have served as the unofficial national 
1 Summary of physical activity guidelines/recommendations for children, by country/major health organisation*

Guidelines/recommendations endorsed specifically for preschoolers:

- United States (guideline): preschoolers should accumulate at least 60 minutes of structured physical activity each day and up to several hours of unstructured physical activity each day, and should not be sedentary for more than 60 minutes at a time, except when sleeping. ${ }^{8}$

United Kingdom (recommendation): Children of preschool age who are capable of walking unaided should be physically active (light-to-vigorous) daily for at least 3 hours, spread throughout the day. ${ }^{9}$

- Ireland (guideline): all children and young people should be active, at a moderate-tovigorous level, for at least 60 minutes every day. ${ }^{10}$

- Australia (recommendation): toddlers ( $1-3$ years) and preschoolers (3-5 years) should be physically active (light-to-vigorous intensity) every day for at least 3 hours, spread throughout the day."

Guidelines endorsed for all children:

- Singapore: accumulate 60 minutes or more moderate-to-vigorous physical activity per day. Build up the 60 minutes with short bouts of 10-15 minutes of physical activity throughout the day. Future national physical activity guidelines (currently in draft) will provide practical guidance for various age groups (including infant to 6 years of age). ${ }^{12}$

Denmark, Finland, Iceland, Norway and Sweden: main target - an increase in the number of children and youths who are physically active for at least 60 minutes per day. ${ }^{13}$

Guidelines/recommendations for preschoolers still under consideration:

- Finland, Austria, and Sweden are in the process of establishing new national recommendations. ${ }^{13}$

- Japan: the education ministry plans to draw up guidelines during the 2011-12 financial year specifying the optimal amount and kind of physical activity preschoolers should be getting. ${ }^{14}$

Guidelines/recommendations for children that do not specifically include preschoolers:

- World Health Organization (recommendations): children aged 5-17 years. ${ }^{15}$

- US (guidelines): children aged 6-17 years. ${ }^{16}$

- Canada (guidelines): children aged 5-11 years. ${ }^{17}$

- New Zealand (guidelines): children and young people aged 5-18 years. ${ }^{18}$

*For further details, see Box 2 (http://mja.com.au/10.5694/mjal1.11015).

guidelines for the US and other global populations, particularly for academics and researchers in the field (Box 2 online). The Institute of Medicine (IOM), an independent organisation in the US, has also released recommendations that toddlers and preschoolers should be physically active for 15 minutes each waking hour (given a 12-hour waking day, this equals around 3 hours of physical activity per day). The IOM guidelines also specify that childcare facilities should ensure that children are active for at least a quarter of the time they spend in the facility. ${ }^{20}$

It is apparent from these guidelines that although researchers are beginning to focus on early childhood, many policymakers are yet to develop guidelines specific to preschool children. This may be due to the lack of literature on the relationship between physical activity and health status in preschool children, as a result of which doseresponses of physical activity for health benefits are difficult to establish. ${ }^{13}$

There is also a lack of consensus on the recommended duration of physical activity for preschool children. While most national and global guidelines recommend 60 minutes of physical activity (light-to-vigorous intensity) per day for all children, including preschoolers, the guidelines endorsed by NASPE and the Australian and UK governments recommend much more $-\geqslant 2$ hours (NASPE) and $\geqslant 3$ hours (Australia and the UK). This, too, is most likely due to the lack of evidence-based literature, particularly in relation to how much physical activity is required for positive health outcomes in childhood and later adulthood. The development of guidelines for children has thus relied heavily on expert opinion and extrapolation from knowledge about adults. It is also important to note that the intensity of physical activity required in this age group is unclear. Current recommendations therefore include all daily movements, which aligns with young children's natural inclinations to be active in intermittent bouts. ${ }^{21}$

Clearly, most current guidelines include an estimated time that children should engage in all types of physical activity (light-to-vigorous intensity). However, some guidelines, such as those of Ireland, are only specific to moderate-to-vigorous activity. Objective monitoring (ie, accelerometry) is considered to be the gold standard when measuring for physical activity. ${ }^{22}$ Yet the selection of cutoff points to quantify different intensities of physical activity remains inconsistent across studies. ${ }^{22}$ Further research is needed to develop an accurate understanding of what intensity and amount of physical activity is required for positive health outcomes in young children.

\section{How physically active are Australian preschool children?}

In a recent study of 427 Australian children aged 3-5 years, less than $17 \%$ of waking time was spent being physically active (light-to-vigorous intensity). This translates into about 36 minutes of moderate-to-vigorous physical activity and 110-120 minutes of light-to-vigorous activity within a 12-hour day. ${ }^{23}$ In another study of 30 children aged 3-5 years, the children were physically active for about 158 minutes per day according to parent reports, with accelerometry indicating an average 34 minutes of moderate-to-vigorous activity per day, ${ }^{24}$ which is also below the Australian recommendation of at least 3 hours per day. ${ }^{9}$ To our knowledge, only one Australian study evaluated Australian children's physical activity against the national recommendation. ${ }^{25}$ It reported that $55.7 \%$ and $79.0 \%$ of a sample of 266 preschool children were physically active for $\geqslant 3$ hours on weekdays and weekend days, respectively, based on parental reports.

We also have cross-sectional data on 220 preschool children (mean age, 3.62 years; SD, 0.76; 106 boys) and report both the average time in light-to-vigorous activity and the percentage of compliance to guidelines. Our sample was recruited from metropolitan Melbourne and Sydney and regional Victoria and New South Wales. We found, using parent proxy report ${ }^{26}$ for all children, and accelerometry in a subsample of 76 children, that the children undertook an average of 154 minutes (SD, 71; range, 26-370 minutes) of activity per day. Only $32.3 \%$ of preschoolers met the guideline of $\geqslant 3$ hours per day of physical activity. ${ }^{26}$

Despite recent literature on Australian preschoolers, it is difficult to ascertain their level of physical activity and whether they are sufficiently active. There are a number of methodological factors influencing our interpretation of physical activity patterns in the preschool years. These include (i) the application of different measurement instruments (parent report versus accelerometer, and inconsistency 
between cut-off points of intensity); (ii) the reporting of different indices of physical activity (percentages versus averages, and minutes per hour compared with minutes per day); and (iii) the use of different benchmark guidelines. For example, if we use a cut-off of 60 minutes or 2 hours, then $93.6 \%$ and $63.2 \%$ of our sample, respectively, would meet the guidelines. In other words, if our children lived in Ireland, the Nordic countries, Singapore or the US, most would be deemed sufficiently active.

\section{Conclusion}

Clearly, we are a long way from forming universal or comparable guidelines for preschool children. In order to compare trends across countries, and to harmonise data collection internationally, empirically supported physical activity guidelines to examine whether children are sufficiently active need to be developed. These guidelines can then be used to summarise what is known about appropriate levels of physical activity in children and to disseminate this knowledge to health professionals so they can help parents attain and maintain regular physical activity in their children's lives. A recent study highlighted that knowledge of physical activity guidelines is associated with adherence to the guidelines for children aged 11-15 years, and that educating parents and children about physical activity guidelines may be beneficial, in particular for families of lower socioeconomic status backgrounds. ${ }^{27}$ Nonetheless, the barriers to developing evidence-based guidelines include methodological issues (such as the application of different measurement instruments), a lack of evidence for the dose-response required for a positive health outcome, and limitations in representative surveys of physical activity in healthy young children.

Future research should focus on how best to examine physical activity reliably in preschool children and how to determine optimal levels of daily physical activity to foster the health and wellbeing of young children. If there are social and cultural factors that influence these optimal levels, these need to be evaluated systematically and rigorously to provide evidence-based recommendations that can then be endorsed by health professionals and early childhood educators and carers across countries, not just within a country. Research questions should focus on optimal dose-responses for health outcomes in overweight or obese preschool children, in particular for maintaining a healthy weight. First, however, epidemiological population survey studies with large samples of healthy children are needed to assess children's natural inclination for activity, which in turn may serve as a benchmark for the development of dose-responses. These studies will need to consider methodological issues of measuring physical activity in children. Without this information base, interventions designed to address childhood obesity and related health outcomes by encouraging recommended levels of physical activity during the formative preschool years will continue to be limited.

Competing interests: No relevant disclosures.

Provenance: Not commissioned; externally peer reviewed.
1 Hills AP, King NA, Armstrong TP. The contribution of physical activity and sedentary behaviour to the growth and development of children and adolescents: Implications for overweight and obesity. Sports Med 2007; 37: 533-545.

2 Janssen I, LeBlanc AG. Systematic review of the health benefits of physical activity and fitness in school-aged children and youth. Int J Behav Nutr Phys Act 2010; 7: 40.

3 Torrance B, McGuire AK, Lewanczuk R, et al. Overweight, physical activity and high blood pressure in children: a review of the literature. Vasc Health Risk Manag 2007; 3: 139-149.

4 Biddle $\mathrm{SJH}$, Asare M. Physical activity and mental health in children and adolescents: a review of reviews. Br J Sports Med 2011; 45: 886-895.

5 Singh AS, Mulder C, Twisk JWR, et al. Tracking of childhood overweight into adulthood: a systematic review of the literature. Obes Rev 2008; 9: 474-488.

6 Trost SG, Sirard JR, Dowda M, et al. Physical activity in overweight and nonoverweight preschool children. Int J Obes Relat Metab Disord 2003; 27: 834-839.

7 Reilly J. Physical activity in early childhood: topic commentary. In: Encyclopedia on early childhood development. Montreal:Centre of Excellence for Early Childhood Development, 2011. http://www.child-encyclopedia.com/documents/ ReillyANGxpl-Physical.pdf (accessed Apr 2011).

8 National Association for Sport and Physical Education. Active start: a statement of physical activity guidelines for children from birth to age 5, 2nd edition. http:// www.aahperd.org/naspe/standards/nationalGuidelines/ActiveStart.cfm (accessed Mar 2011).

9 Department of Health. UK physical activity guidelines. http://www.dh.gov.uk/en/ Publicationsandstatistics/Publications/PublicationsPolicyAndGuidance/DH_ 127931 (accessed Jul 2011).

10 Get Ireland Active. Children and young adults: guidelines for children and young people (aged 2-18). http://www.getirelandactive.ie/get-the-guidlines/childrenand-young-adults/ (accessed Mar 2011).

11 Australian Government Department of Health and Ageing. Physical activity guidelines. http://www.health.gov.au/internet/main/publishing.nsf/Content/ health-pubhlth-strateg-phys-act-guidelines\#rec_0_5 (accessed Mar 2011).

12 Health Promotion Board. National Healthy Lifestyle Campaign 2010. http:// hpb.gov.sg/uploadedFiles/HPB_Online/News_and_Events/News/2010/ NHLC2010AnnexeE.pdf (accessed Jun 2011).

13 Becker W, Lyhne N, Pederson A, et al. Nordic Nutrition Recommendations 2004 integrating nutrition and physical activity. Scand J Nutr 2004; 48: 178-187.

14 Yomiuri Shimbun. Ministry to set exercise guidelines for preschoolers. Daily Yomiuri Online 2011; 6 Jan. http://www.yomiuri.co.jp/dy/national/T110105003528.html (accessed May 2011)

15 World Health Organization. Global recommendations on physical activity for health. Geneva:WHO, 2010. http://whqlibdoc.who.int/publications/2010/ 9789241599979_eng.pdf (accessed Mar 2011).

16 US Department of Health and Human Services. Physical activity guidelines for Americans. Chapter 3: Active children and adolescents. http://www.health.gov/ PAGuidelines/guidelines/chapter3.aspx (accessed Apr 2011).

17 Canadian Society for Exercise Physiology. Canadian physical activity guidelines. Ottawa: CSEP, 2011. http://www.csep.ca/CMFiles/Guidelines/CanadianPhysical ActivityGuidelinesStatements_E.pdf (accessed May 2011).

18 Sport and Recreation New Zealand. Physical activity guidelines for children and young people (5-18 years old). http://www.sparc.org.nz/en-nz/young-people/ Activity-Guidelines-5-18-Years/ (accessed Jan 2012).

19 Centers for Disease Control and Prevention. Physical activity for everyone: How much physical activity do children need? http://www.cdc.gov/physicalactivity/ everyone/guidelines/children.html (accessed Apr 2011).

20 Early Childhood Obesity Prevention Policies Committee on Obesity Prevention Policies for Young Children. Physical activity. In: Birch LL, Parker L, Burns A, editors. Early childhood obesity prevention policies. Washington, DC: National Academies Press, 2011.

21 Cliff DP, Janssen X. Levels of habitual physical activity in early childhood. In: Encyclopedia on early childhood development. Montreal: Centre of Excellence for Early Childhood Development, 2011. http://www.child-encyclopedia.com/ documents/Cliff-JanssenANGxpl.pdf (accessed Apr 2011).

22 Beets MW, Bornstein D, Dowda M, Pate RR. Compliance with national guidelines for physical activity in US preschoolers: measurement and interpretation. Pediatrics 2011; 127:658-664.

23 Hinkley T, Salmon J, Hesketh K, et al. Characterising preschool children's physical activity: the HAPPY study [abstract]. J Sci Med Sport 2010; 12: el69.

24 Wen LM, Van der Ploeg HP, Kite J, et al. A validation study of assessing physical activity and sedentary behaviour in children aged 3-5years. Pediatr Exerc Sci 2010; 22: 408-420.

25 Okley AD, Trost SG, Steele JR, et al. Adherence to physical and electronic media guidelines in Australian pre-school children. J Paediatr Child Health 2009; 45: 5-8

26 Dwyer GM, Hardy LL, Peat JK, Baur LA. The validity and reliability of a home environment preschool-age physical activity questionnaire (Pre-PAQ). Int J Behav Nutr Phys Act 2011; 8: 86.

27 Roth M, Stamatakis E. Linking young people's knowledge of public health guidelines to physical activity levels in England. Pediatr Exerc Sci 2010; 22: 467-476. 
Specific for age group

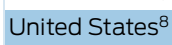

NASPE guidelines: preschoolers should accumulate at least 60 minutes of structured physical activity and up to several hours of unstructured physical activity each day, and should not be sedentary for more than 60 minutes at a time, except when sleeping.*

United Kingdom ${ }^{9}$ Recommendations: children of preschool age who are capable of walking unaided should be physically active daily for at least 3 hours, spread throughout the day.

Ireland ${ }^{10}$ Guidelines: all children and young people should be active at a moderate-to-vigorous level for at least 60 minutes every day. Activity should include muscle-strengthening, flexibility and bonestrengthening exercises three times a week.

Australia" Recommendations: toddlers ( $1-3$ years) and preschoolers (3-5 years) should be physically active every day for at least 3 hours, spread throughout the day. This can include light activity like standing up, moving around and playing, as well as more vigorous activity like running and jumping. Active play is the best way for young children to be physically active.

Including preschoolers

Singapore ${ }^{12}$

Current Health Promotion Board guidelines: accumulate 60 minutes or more moderate-to-vigorous physical activity per day. Build up the 60 minutes with short bouts of 10-15 minutes throughout the day. Future guidelines (in draft): the national physical activity guidelines will provide practical guidance for various age groups $(<6,7-18,19-$ $50,>51$ years) on the types and volume of physical activities that decrease morbidity, premature death and enhance quality of life.

Denmark, Guidelines: main target for country - an increase in the number of Finland, Iceland, children and youth who are physically active for at least 60 minutes Norway and per day. The activity can probably be divided into shorter intervals of Sweden ${ }^{13}$ per day. The activity can probably be divided into
physical activity during the course of the day.

\section{Preschooler guidelines under consideration}

Published Apr 2011

Published Oct $\quad 1-5$ years 2010

11 Jul 2011

Published 2009 2-18 years children who are capable of walking

All children $<5$ years of age should minimise the amount of time spent being sedentary (being restrained or sitting) for extended periods (except when sleeping).

None specified.

Children $<2$ years of age should not spend any time watching television or using other electronic media (DVDs, computer and other electronic games); for children $2-5$ years of age, these activities should be limited to less than 1 hour per day. Infants, toddlers and preschoolers should not be sedentary, restrained or kept inactive for more than 1 hour at a time, except when sleeping.

"Youth" - not currently specified

"Limit extended periods of inactivity such as TV watching, video and handheld games and online social games". ${ }^{\dagger}$ Time limits and age range are not specified.

Published $2004 \quad$ Not specified None specified.

Finland, Austria and Sweden ${ }^{13}$

Japan $^{14}$

\section{In}

To help reverse the decline in children's physical strength, the education ministry plans to draw up guidelines next fiscal year specifying the optimal amount and kind of physical activity preschoolers should be getting.

\section{Preschoolers not specifically included}

$\mathrm{WHO}^{15}$

No recommendations for children aged $<5$ years. The recommendations state that although children in this age range benefit from being active, more research is needed to determine what dose of physical activity provides the greatest health benefits. The age groups selected take into consideration the nature and availability of the scientific evidence relevant to the selected outcomes. Recommendations for children and youth aged 5-17 years: accumulate at least 60 minutes of moderate-to-vigorous physical activity daily. Most of the daily physical activity should be aerobic. Vigorous activities, including those that strengthen muscle and bone, should be incorporated at least three times per week.

United States ${ }^{16}$ Physical Activity Guidelines for Americans: children and adolescents should do 60 minutes or more of physical activity daily. The Physical Activity Guidelines Advisory Committee did not review evidence for children $<\sigma$ years of age, although it states that physical activity for infants and young children is necessary for healthy growth and development. Children $<6$ years of age should do physical activity appropriate for their age and stage of development.

The CDC guidelines ${ }^{19}$ are based on 2008 Physical Activity Guidelines for Americans described above.

Pending

Statement published Jan

2011;

development of

guidelines

pending

\section{Published $2010 \quad$ 5-17 years $\quad$ None specified.}

Published 2008 6-17 years There are no current Canadian physical activity guidelines for children aged $<5$ years, and this new set of guidelines does not specifically address this age group. It is stated that work is currently underway in the physical activity research community in Canada to develop official physical activity and sedentary activity guidelines that address this age group. For health benefits, children aged 5-11 years should accumulate at least 60 minutes of moderate-to-vigorous physical activity daily. Vigorous activities should be done at least 3 days per week.

New Zealand ${ }^{18} \quad$ There are no specific guidelines for children aged $<5$ years but the current guidelines explain that movement is important from birth. Active movement is encouraged for healthy development - children learn from movement and physical activity. The guidelines state that throughout each day, children should be doing 60 minutes or more of moderate-to-vigorous physical activity.

\section{Not yet specified None specified.}

Will focus on 3-5 None specified. years

\begin{tabular}{|c|c|c|}
\hline $\begin{array}{l}\text { CDC website last } \\
\text { updated Nov } 2011\end{array}$ & $6-17$ years & $\begin{array}{l}\text { No global guidelines for sedentary behaviour. } \\
\text { American children are expected to follow the } \\
\text { Physical Activity Guidelines. }\end{array}$ \\
\hline $\begin{array}{l}\text { Published Jan } \\
2011\end{array}$ & 5-11 years & $\begin{array}{l}\text { In } 2011 \text {, after releasing the physical activity guidelines, } \\
\text { the government released sedentary behaviour } \\
\text { guidelines for children aged } 5-11 \text { years. }{ }^{.} \text {These } \\
\text { suggest limiting recreational screen time to no } \\
\text { more than } 2 \text { hours per day. No guidelines for children } \\
\text { aged < } 5 \text { years. }\end{array}$ \\
\hline
\end{tabular}

Published $2007 \quad 5-18$ years

Alobal guidelines for sedentary behaviour. Physical Activity Guidelines.

2011, after releasing the physic the government released sedentary behaviour suggest limiting recreational screen time to aged $<5$ years.

No guidelines for children aged $<5$ years. For children
The American Academy of Pediatrics recommends that children aged $\leqslant 2$ years should not watch television and that children aged $\geqslant 2$ years should limit media time to no more than $1-2$ hours of quality programming daily. ${ }^{\ddagger}$ These recommendations have been unofficially adopted as the guidelines for American children. aged 5-18 years, less than 2 hours a day (out of school hours) in front of the television, computers and game consoles is suggested.

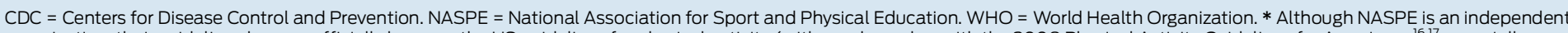

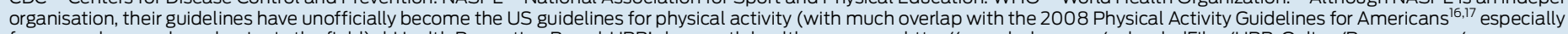
for researchers and academics in the field). † Health Promotion Board. HPB's key youth health messages. http://www.hpb.gov.sg/uploadedFiles/HPB_Online/Programmes/

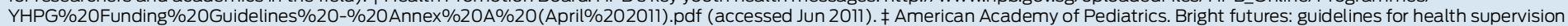

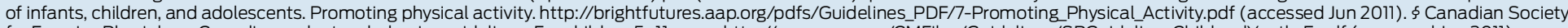

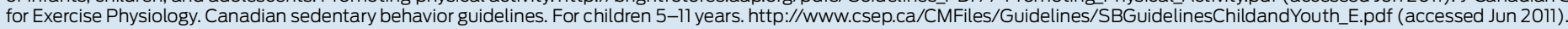

